\title{
GMR
}

\section{Distribution of constitutive heterochromatin in Pachycoris torridus (Hemiptera, Scutelleridae) with different chromatic patterns}

T.S. Souza-Firmino ${ }^{1}$, K.C.C. Alevi ${ }^{2}$, L.L.V. Pereira ${ }^{1}$, E.R.S. Souza ${ }^{1}$, F.C.S. Júnior ${ }^{1}$, C.A. Banho', G.O. Carmo ${ }^{1}$ and M.M. Itoyama ${ }^{1}$

${ }^{1}$ Laboratório de Citogenética e Molecular de Insetos,

Departamento de Biologia, Instituto de Biociências, Letras e Ciências Exatas,

Universidade Estadual Paulista "Júlio de Mesquita Filho", São José do Rio Preto,

SP, Brasil

${ }^{2}$ Laboratório de Biologia Celular, Departamento de Biologia,

Instituto de Biociências, Letras e Ciências Exatas,

Universidade Estadual Paulista “Júlio de Mesquita Filho", São José do Rio Preto,

SP, Brasil

Corresponding author: K.C.C. Alevi

E-mail: kaiochaboli@hotmail.com

Genet. Mol. Res. 14 (4): 15749-15753 (2015)

Received February 2, 2015

Accepted July 14, 2015

Published December 1, 2015

DOI http://dx.doi.org/10.4238/2015.December.1.26

ABSTRACT. The stink bug Pachycoris torridus is a pest of great agricultural importance due to its records on culture of physic nut (Jatropha curcas), which is the raw material for biodiesel production. An interesting feature of this insect is its high phenotypic variability, a characteristic that resulted in it being classified as a new species on eight separate occasions. In the suborder Heteroptera, the heterochromatin pattern is specific and often allows species to be differentiated. To confirm whether there is differentiation between specimens of $P$. torridus with different color patterns (yellow, orange, brown, and red), samples were analyzed cytogenetically using the C-banding method. During meiotic prophase, the four color patterns analyzed showed a large heterochromatic 
chromocenter, consisting of a combination of both sex chromosomes (X and $\mathrm{Y}$ ). Thus, the present study reports chromosomal homogeneity in different color patterns of $P$. torridus and highlights the importance of this tool in the description of new species.

Key words: Heteroptera; Spermatogenesis; Chromosomal homogeneity; Meiosis

\section{INTRODUCTION}

The order Hemiptera is composed of three suborders: Auchenorrhyncha, Heteroptera, and Sternorrhyncha (Cryan and Urban, 2012). The Heteroptera suborder is of great economic importance, because many species can interfere with agricultural crops in the form of pests (phytophagous), they can act as biological controls of insect pests (predators), and they can interfere with public health (hematophagous), as vectors of the protozoan Trypanosoma cruzi, which is the etiologic agent of Chagas disease (Schuh and Slater, 1995).

In terms of phytophagous, the species Pachycoris torridus (Hemiptera: Scutelleridae) is the only member of the family Scutelleridae with agricultural importance in Brazil. This insect is popularly known as the "stink bug of physic nut", due to their attacks on physic nut (Jatropha curcas) cultures, which is the raw material for biodiesel production (Silva el al., 1968). However, this is not the only plant in which the stink bug is found. It is polyphagous and is thus a pest of various agricultural crops, including rice, guava, orange, cassava, and mango (Silva et al., 1968). These are widely distributed in America, and can be found from the United States to Argentina (Froeschner, 1988).

P. torridus exhibits variation in the pattern of spots, and the color of these spots is diverse, varying from red to yellow (Monte, 1937). In total, 27 different staining patterns have been reported (Souza et al., 2012), a characteristic that led this bug to be described as a new species on eight different occasions (Costa Lima, 1940).

Due to its economic importance, several papers have recently been published about this species. Gomes et al. (2013) described some morphological characteristics, such as the oval testicles, transparent peritoneal sheath, and the seven elongated lobes. In a biological study by Gabriel and Franco (2012), the longevity of this Scutelleridae was confirmed, and it was found to live as long as 600 days, and Rodrigues et al. (2011) reported a short period of development, with an average of 85.6 days between the egg and adult stages. Using these features, SouzaFirmino et al. (2015) reported the presence of $P$. torridus in 15 Brazilian states and emphasized their infestations in physic nut culture.

However, genetic analyses of these insects are scarce, and are restricted to the description of the karyotype, namely, $2 n=12(10 A+X Y)$ (De Souza et al., 2014). Therefore, this study aimed to describe the heterochromatic pattern of four different color patterns of $P$. torridus (yellow, orange, brown, and red), and determine whether intraspecific chromosomal variations exist.

\section{MATERIAL AND METHODS}

Three adult males each of $P$. torridus individuals with different color spots (yellow, orange, brown, and red) were used (Figure 1). These were collected from the Municipal reservoir in São 
José do Rio Preto, Sao Paulo, Brazil, and transported in pots to the Laboratory of Cytogenetics and Molecular of Insects (LACIMI) of UNESP/IBILCE. The species were fixed in methanol/acetic acid (3:1) and the testicles were extracted, dissected, and stained using the cytogenetic technique of C-banding (Sumner, 1972). Images were captured on a microscope (ZEISS Axio Scope A1), using AXIO VISION LE version 4.8 for image analysis.
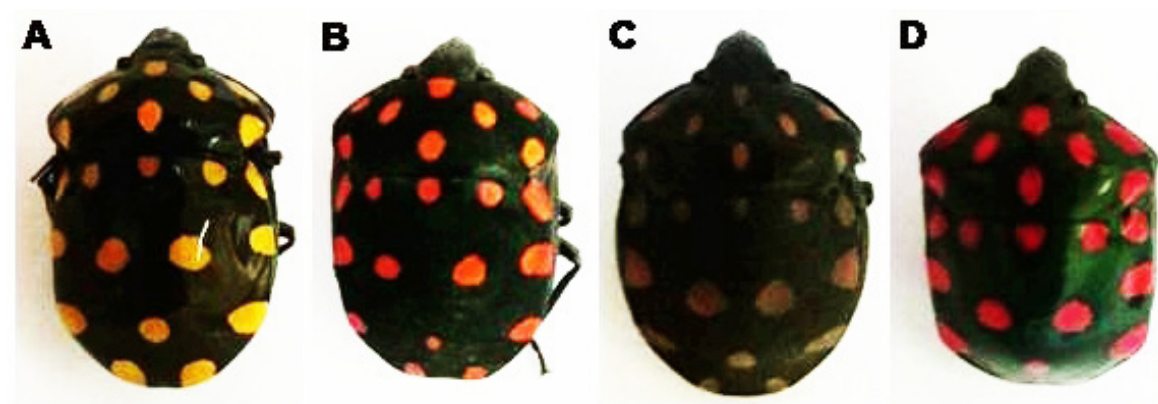

Figure 1. Specimens of Pachycoris torridus representing the different color patterns, (A) yellow, (B) orange, (C) brown, and (D) red.

\section{RESULTS}

During the initial prophase, heterochromatic blocks were clearly visible because of the decondensed chromatin. Analysis of prophase revealed that all chromatic variations of $P$. torridus had heterochromatic blocks in the chromocenter only, which were formed by the sex chromosomes ( $\mathrm{X}$ and $\mathrm{Y}$ ) (Figure 2A-D).
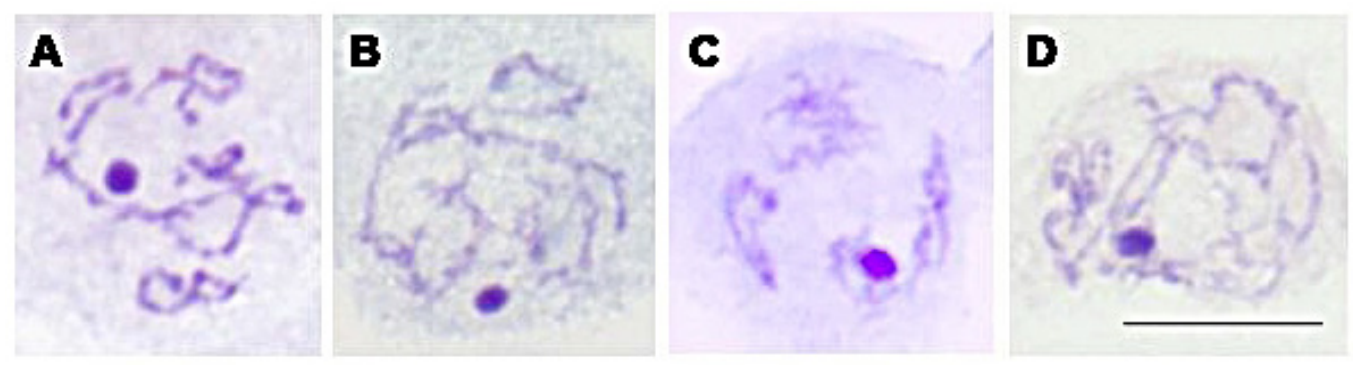

Figure 2. Heterochromatic pattern of the different color patterns of Pachycoris torridus, (A) yellow, (B) orange, (C) brown, and (D) red. Note that only the sex chromosomes appear heterochromatic. Bar: $10 \mu \mathrm{m}$.

\section{DISCUSSION}

The disposition of constitutive heterochromatin in Heteroptera chromatin and chromosomes is an important tool in taxonomic and evolutionary studies, and in population genetics (Crossa et al., 2002; Panzera et al., 1992, 1997, 2004; Gómez-Palacio et al., 2008; Alevi et al., 2013, 2014a,b, 2015a,b,c; Gabriela et al., 2013). 
Intraspecific chromosomal variations in the heterochromatic block have been reported in Triatoma infestans (Panzera et al., 1992, 2004), T. sordida (Panzera et al., 1997), Panstrongylus geniculatus (Crossa et al., 2002), and Rhodnius pallescens (Gómez-Palacio et al., 2008). This feature is extremely important to our understanding of the evolutionary history of $T$. infestans, since it is possible to differentiate populations in the Andean and non-Andean and to associate the loss of heterochromatin with the occupation of different environments (Panzera et al., 1992). There was no variation in the distribution of heterochromatin blocks between $P$. torridus individuals displaying different color patterns. The absence of intraspecific variation was also observed for different populations of T. brasiliensis (Panzera et al., 2000), R. neglectus (Alevi et al., 2015a), and P. megistus (Alevi et al., 2015b).

P. torridus has been described eight times as a new species (Costa Lima, 1940). In present studies, morphological data should be combined with other tools to validate the specific status of a taxon. Cytogenetic analyses are important taxonomic tools, which often help to differentiate species based on morphology and evolution, such as species of the genus Rhodnius, which are considered to be cryptic species (morphologically identical) (Pita et al., 2013). In the case of $P$. torridus, the results show that if classical cytogenetic analysis had been used in the initial analyses of the eight morphotypes, the errors in its identification could have been avoided, because all samples would present the same number of chromosomes and the same pattern of bands.

Thus, the present study describes the heterochromatic pattern of $P$. torridus, reports chromosomal homogeneity in different color patterns, and highlights the importance of this tool in the description of new species. We emphasize that further studies on experimental crosses of hybrids and molecular analyzes must be conducted in order to clarify how the segregation of color patterns occurs in these economically important insects.

\section{Conflicts of interest}

The authors declare no conflict of interest.

\section{ACKNOWLEDGMENTS}

Research supported by Fundação de Amparo à Pesquisa do Estado de São Paulo (FAPESP process \#2008/09166-0), Fundação de Desenvolvimento da UNESP (FUNDUNESP), Fundação de Apoio à Pesquisa e Extensão de São José do Rio Preto (FAPERP process \#11/2015), and Conselho Nacional de Desenvolvimento Científico e Tecnológico (CNPq).

\section{REFERENCES}

Alevi KC, Mendonça PP, Pereira NP, Guerra AL, et al. (2013). Distribution of constitutive heterochromatin in two species of triatomines: Triatoma lenti Sherlock and Serafim (1967) and Triatoma sherlocki Papa, Jurberg, Carcavallo, Cerqueira \& Barata (2002). Infect. Genet. Evol. 13: 301-303.

Alevi KC, Rosa JA and Azeredo-Oliveira MT (2014a). Cytotaxonomy of the Brasiliensis subcomplex and the Triatoma brasiliensis complex (Hemiptera: Reduviidae: Triatominae). Zootaxa 3838: 583-589.

Alevi KC, Rosa JA and Azeredo-Oliveira MT (2014b). Distribution of constitutive heterochromatin in Triatoma melanocephala (Hemiptera, Triatominae). Genet. Mol. Res. 13: 7899-7903.

Alevi KCC, Rodas LAC, Tartarotti E, Azeredo-Oliveira MTV, et al. (2015a). Entoepidemiology of Chagas disease in the Western region of the State of São Paulo from 2004 to 2008, and cytogenetic analysis in Rhodnius neglectus (Hemiptera, Triatominae). Genet. Mol. Res. 14: 5775-5784. 
Alevi KCC, Nunes GM, Rosa JA and Azeredo-Oliveira MTV (2015b). Homogeneity chromosome in different populations of Panstrongylus megistus in Brazil. Rev. Cienc. Farm. Basic. Apl. 36: 307-310.

Alevi KCC, Oliveira J, Moreira FFF, Jurberg J, et al. (2015c) Chromosomal characteristics and distribution of constitutive heterochromatin in the Matogrossensis and Rubrovaria subcomplexes. Infect. Genet. Evol. 33: 158-162.

Costa Lima AC (1940). Insects of Brazil. Hemiptera. Educational Series Number. 3 National School of Agronomy, Rio de Janeiro.

Crossa RP, Hernández M, Caraccio MN, Rose V, et al. (2002). Chromosomal evolution trends of the genus Panstrongylus (Hemiptera, Reduviidae), vectors of Chagas disease. Infect. Genet. Evol. 2: 47-56.

Cryan JR and Urban JM (2012). Higher-level phylogeny of the insect order Hemiptera: is Auchenorrhyncha really paraphyletic? Syst. Entomol. 37: 7-21.

De Souza HV, Castanhole MM, Gomes MO, Murakami AS, et al. (2014). Meiotic behavior of 18 species from eight families of terrestrial Heteroptera. J. Insect Sci. 14: 149.

Froeschner RC (1988). Family Scutelleridae Leach, 1815. The shield bugs. In: Catalog of the Heteroptera or true bugs, of Canada and the Continental United States (Henry TJ and Froeschner RC, eds.). Brill, New York, 684-693.

Gabriel D and Franco DAS (2012). Biological and morphological aspects of Pachycoris torridus Scopoli, 1772 (Hemiptera: Scutelleridae) created with physic nut Jatropha curcas L., 1753, in the Laboratory. Científica 40: 156-163.

Gabriela CM, Papeschi AG and Bressa MJ (2013). The significance of cytogenetics for the study of karyotype evolution and taxonomy of water bugs (Heteroptera, Belostomatidae) native to Argentina. Comp. Cytogenet. 7: 111-129.

Gomes MO, Castanhole MMU, De Souza HV, Murakami AS, et al. (2013). Morphological aspects of the testes of 18 species of terrestrial of Heteroptera from Northwestern São Paulo (Brazil). Biota Neotrop. 13: 132-135.

Gómez-Palacio A, Jaramillo-Ocampo N, Triana-Chávez O, Saldaña A, et al. (2008). Chromosome variability in the Chagas disease vector Rhodnius pallescens (Hemiptera, Reduviidae, Rhodniini). Mem. Inst. Oswaldo Cruz 103: $160-164$.

Monte O (1937). Some variations in designs and color of Pachycoris torridus (Scopoli). Campo 8: 71.

Panzera F, Alvarez F, Sanchez-Rufas J, Pérez R, et al. (1992). Heterochromatin polymorphism in holocentric chromosomes of Triatoma infestans (Hemiptera: Reduviidae). Genome 35: 1068-1074.

Panzera F, Hornos S, Pereira J, Cestau R, et al. (1997). Genetic variability and geographic differentiation among three species of Triatomine bugs (Hemiptera-Reduviidae). Am. J. Trop. Med. Hyg. 57: 732-739.

Panzera F, Pérez R, Nicolini P, Hornos S, et al. (2000). Chromosome homogeneity in populations of Triatoma brasiliensis Neiva 1911 (Hemiptera-Reduviidae-Triatominae). Cad. Saúde Pública 16: 83-88.

Panzera F, Dujardin JP, Nicolini P, Caraccio MN, et al. (2004). Genomic changes of Chagas disease vector, South America. Emerging Infect. Dis. 10: 438-446.

Pita S, Panzera F, Ferrandis I, Galvão C, et al. (2013). Chromosomal divergence and evolutionary inferences in Rhodniini based on the chromosomal location of ribosomal genes. Mem. Inst. Oswaldo Cruz 108: 376-382.

Rodrigues SR, Oliveira HN, Santos WT and Abot AR (2011). Aspects biological and damage of Pachycoris torridus in physic nut. Bragantia 70: 356-360.

Schuh RT and Slater JA (1995). True bugs of the world. Cornell University Press, Ithaca.

Silva AGA, Gonçalves CR, Galvão DM, Gonçalves AJL, et al. (1968). Fourth catalog of insects that live in plants in Brazil. Their parasites and predators. Part 2, volume 1, insects, hosts and natural enemies. Ministry of Agriculture, Rio de Janeiro.

Souza GK, Pikart TG, Oliveira HN, Serrão JE, et al. (2012). Color polymorphism in Pachycoris torridus (Hemiptera: Scutelleridae) and its taxonomic implications. Rev. Chil. Hist. Nat. 85: 357-359.

Souza-Firmino TS, Alevi KCC, Pereira LLV, Banho CA, et al. (2015). Occurrence of Pachycoris torridus (Scopoli, 1772) (Hemiptera: Scutelleridae) on Physic Nut (Jatropha curcas) in Northwest of São Paulo, Brazil. Entomol. Ornithol. Herpetol. 4: 135.

Sumner AT (1972). A simple technique for demonstrating centromeric heterochromatin. Exp. Cell Res. 75: $304-306$. 